\title{
Investigation of Effectiveness of High-Intensity Functional Exercise on Older Adults: A Systematic Review
}

\author{
Hakan Gulmez ${ }^{1}$, Betül Taşpınar ${ }^{1}$, and Ferruh Taşpınar ${ }^{1}$ \\ ${ }^{1}$ İzmir Democracy University
}

February 19, 2021

\begin{abstract}
Objective: The aim of this systematic review was to investigate the effectiveness of HIFE on physiologic and psychological functions in older adults aged [?]65 years. Methods: This systematic review was designed according to the PEDro scale. PubMed, Web of Science and Scopus databases were used for the systematic searching. Total 1340 studies were identified. The full texts of these studies were examined in respect of the study inclusion and exclusion criteria, and finally 9 studies met the criteria and were included for evaluation. Results: Physical functions and psychosocial functions were evaluated via questionnaires and tests. According to results of the included studies HIFE was effective in respect of the evaluated parameters. Conclusion: As a result of this systematic review HIFE is effective on physical functions and hemodynamic responses but the effect on psychosocial functions are controversially, at the same time there were no reports of negative effects.
\end{abstract}

\section{Hosted file}

manuscript3.docx available at https://authorea.com/users/396675/articles/509794investigation-of-effectiveness-of-high-intensity-functional-exercise-on-older-adultsa-systematic-review 


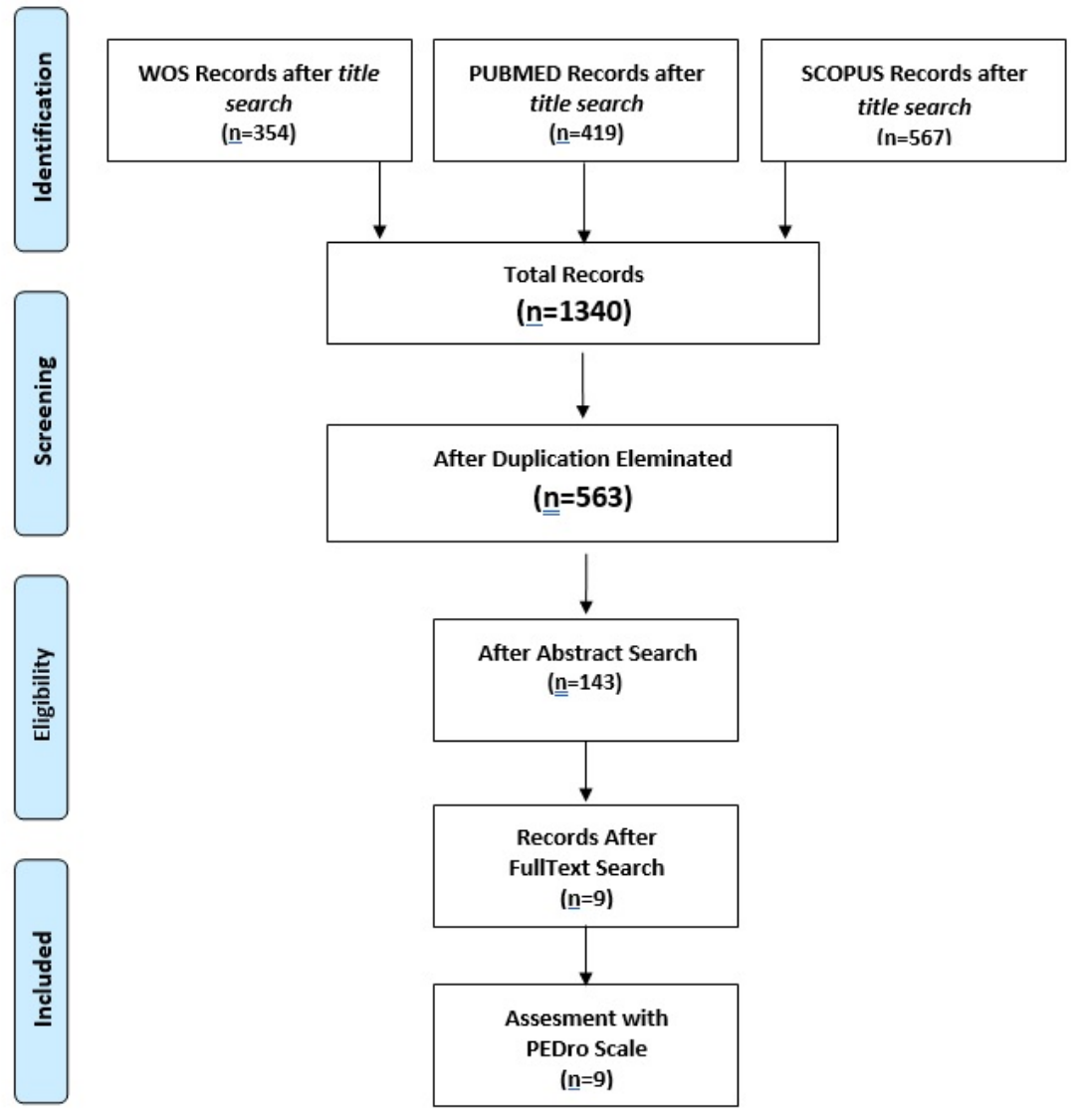

